\title{
Traditional knowledge in weathering effects of climate variability on upland farming among Buhid Farmers in Occidental Mindoro, Philippines
}

\author{
Susanita G. Lumbo \\ Occidental Mindoro State College, San Jose, Occidental Mindoro, Philippines. \\ E-mail: shannie.lumbo@gmail.com
}

How to Cite: Lumbo, S.G. (2018). Traditional knowledge in weathering effects of climate variability on upland farming among Buhid Farmers in Occidental Mindoro, Philippines. Int. J. Agr. Syst. 6(2): 164-171

\begin{abstract}
This exploratory study highlights the tradidional knowledge employed by Buhid farmers in weathering effects of climate variability on upland farming. A total of 100 farmers from two Buhid settlements participated in the study. They are either young or middled-aged and with small or big households. Less than half of them are affiliated to community organizations. Majority have neither attended relevant trainings and seminars nor have been involved in community initiatives relating to climate variability adaptation. The farmers attribute poor soil, low yield, poor yield quality, water scarcity, depletion of natural resources, and crop pest and diseases as manifest effects of climate variability. They practice rituals, ecological farming, and food substitutes to counter negative effects of climate variability on upland farming. The Buhids' organizational affiliation, trainings and seminars attended, and community involvement were found associated to the traditional knowledge employed in adapting to effects of climate variability on upland farming.
\end{abstract}

Copyright @ 2018 IJAS. All rights reserved.

Keywords:

climate variability; traditional knowledge; Buhid Mangyans

\section{Introduction}

The Buhid is an ethnolinguistic group or indigenous people (IP) inhabiting the uplands of Occidental Mindoro, Philippines. The Buhid derives its name from a Mangyan word "Sambuhid," which refers to an elevated land or mountainous area. They are engaged in swidden farming, which is their primary source of livelihood [8]. The Buhids as shifting cultivators are content with having a simple life, but with the course of events such as the influx of modernization, ballooning population, and scarcity of lands, the Buhids have learned to intensify cultivation to produce food not only for subsistence but also for market [7].

The IPs are among the Philippines' poorest sectors. The International Fund for Agricultural Development reported that they experience seasonal to chronic food shortages during the year [6]. Among the causes of poverty identified are poor farm productivity and income, smaller farm sizes, and unsustainable farm practices [5]. In a similar context, the Focus on Global-South Philippines revealed that environmental destruction and climate change contribute to poverty and food insecurity in the 
uplands.[3]. This scenario makes development advocates realize the usefulness of indigenous knowledge (IK) in coping with such life's difficulties. IK that includes wisdom, knowledge, and practices of indigenous people (IP) is believed to have played a significant part in solving problems resulting from climate change and variability [4]. Scientists recognized it as most effective in promoting sustainable development ${ }^{[2]}$.

The IPs who are most vulnerable to effects of climate changes have established a wide array of agricultural knowledge fitted to their condition and habitat. The indigenous agricultural practices enabled them to sustain food production [10]. Thus, this exploratory study intended to document the Buhid farmers' utilization of traditional knowledge in coping with effects of climate variability on upland farming. Findings of the study can be used in providing valuable insights in coming up with adaptation strategies [9] in other similar circumstances. Local knowledge is significant for preserving biodiversity, which is considered a very successful adaptation strategy [1].

This study determined the Buhid Mangyans' experiences as to effects of climate variability on upland farming and traditional knowledge employed to cope with the phenomenon. Specifically, this endeavored to realize the following objectives: 1) to describe the Buhid Mangyans in terms of their socio-economic characteristics such as age, household size, community organizations membership, trainings and seminars attended relative to climate variability adaptation, and community involvement in climate variability adaptation, 2) to determine the experiences of the Buhids relative to effects of climate variability on upland farming, 3) to describe the traditional knowledge employed to adapt to climate variability, 4) find out the relationship between the Buhids' socio-economic characteristics and the traditional knowledge employed to adapt to climate variability.

\section{Method}

This study was conducted in Sitios Danlog and Batoili- two of the Buhid Mangyan settlements located in Barangay Monteclaro, San Jose, Occidental, Mindoro, Philippines. This employed triangulation data-gathering techniques such as household interview, key informant interview,focus group discussion, and use of secondary data. A total of 100 Buhids aged 25 years and older participated in the study. These people were chosen on the assumption that they can compare climatic conditions ten years ago and nowadays. A preliminary survey of indigenous farming knowledge was done in Sitio Danlog. This involved the community elders and individuals who have appreciable knowledge on climate variability. The information gathered were used in constructing the interview schedule. Part of the conceptualization of the study was securing of necessary permit and prior consent from the Buhid leaders of the study areas. This was facilitated by a Buhid Agriculture student enrolled in Occidental Mindoro State College (OMSC). Getting the full trust and confidence of the participants was a bit easier because of the long established friendship between OMSC and the Buhid communities.

\section{Results and Discussion}

\subsection{The Buhid Mangyans' socio-economic characteristics}

The Buhids' socio-economic characteristics considered in the study are age, household size, community organizations membership, trainings and seminars on climate adaptation attended, and community involvement in climate climate change 
adaptation. In terms of age, majority of the respondents' age ranged from young to middle-aged. Less than $20 \%$ are 60 years old and above (Table 1). This means that the Buhids are still physically able to perform farm work and to actively get involved in any community-based climate variability adaptation initiatives.

The household sizes varied from small to big. In terms of organizational membership, more than half $(55.00 \%)$ were not affiliated to any community organization. The rest were members of Sadik Habanan Buhid (33.33\%), Sapang Pa (8.00\%), and Hakbang Mo $(4.00 \%)$. Sadik Habanan Buhid, which means "United community of Buhid" is a federation of Buhid Mangyans in Occidental Mindoro, Philippines. Sapang Pa means Sentrong Pangkalakalan ng Tribung Buhid (Business Center of Buhid Tribe) is an organization initiated by Plan International. This organization takes charge of Plan's sponsored livelihood projects for the Buhids such as animal dispersal, coconut production, fruit trees plantation, and others. Similarly, Hakbang Mo is a Plan initiated livelihood project (bead making) for women.

Table 1. The Buhid farmers' socio-economic characteristics.

\begin{tabular}{lcc}
\hline Socio-economic characteristics & Frequency & Percentage \\
\hline Age & & \\
Young (25-39) & 45 & 45.0 \\
Middle-aged (40-59) & 38 & 38.0 \\
Old (60 and above) & 17 & 17.0 \\
Household size & 33 & 33.0 \\
Small (4 and below) & 37 & 37.0 \\
Medium (5-7) & 30 & 30.0 \\
Big (8 and above) & & \\
Community organizations' membership & 33 & 33.0 \\
Habanan Buhid & 8 & 8.0 \\
Sapang Pa & 4 & 4 \\
Hakbang Mo & 55 & 55 \\
None & & \\
Trainings and seminars attended relative to & & \\
climate variability adaptation & 1 & 1 \\
Health & 2 & 2 \\
Tree planting & 1 & 1 \\
Climate change/variability & 96 & 96 \\
None & & \\
Community involvement in variability adaptation & 1 & 1 \\
$\quad$ Feeding program & 1 & 1 \\
Asking help from LGU & 23 & 23 \\
Ritual & 75 & 75 \\
$\quad$ None &
\end{tabular}

In terms of seminars and trainings related to climate variability attended, majority $(96.00 \%)$ said they have not attended any. The Buhids forgot they were recipients and partners of two OMSC-initiated extension programs such as the Sustainable Agricultural Development Extension Program (SADEP), which started in 2002 and the Poverty Alleviation Promotion for the Environment and Livelihood of Buhids (PAPEL Buhid) launced in 2006. Sitio Danlog was a recipient of at least three trainings related to sustainable agriculture conducted in 2008 and 2010. On the other hand, Sitio Bato-ili is a host and beneficiary of PAPEL Buhid for a period of five years (2006-2011). PAPEL 
Buhid had various component projects such as agriculture, environment, livelihood, education, and health. Related training and seminars were regularly conducted during those years and even after the program terminated in 2011. Training and seminars in natural resourcement management, organic farming, nursery establishment, and others related to adaptation strategies were introduced in the community. This study therefore argued that the Buhids had attended various trainings related to climate variability adaptation but they had a problem on recall. They did not also realize that those activities they had participated were climate variability-related adaptation activities. Majority $(75.00 \%)$ of the Buhids claimed they had no involvement in climate variability adaptation activities. They had also not realized the livelihood activities introduced in their communities by OMSC and Plan were climate variability adaptation initiative. Some $23.00 \%$ were involved in rituals done to avert effects of climate variability on upland farming.

\subsection{Buhid's experiences relative to effects of climate variability on upland farming}

The Buhids' extent of having experienced relative effects of climate variabilty on upland farming were explored. The degree to which the farmers experience such particular phenomenon was rated using the 3-point scale: 3 (always), 2 (sometimes), and 1 (never). The Buhids revealed they "sometimes experienced" poor soil, low yield, water scarcity, poor yield quality, lack of food, and depletion of natural resources. On the other hand, emergence of pests and lack of food were "always experienced" as manifest effects of climate variability on upland farming (Table 2). This implies that the Buhids were not exempted from experiencing the manifest effects of climate variability on their swidden farming.

Table 2. Experiences relative to effects of climate variability on upland farming.

\begin{tabular}{lcl}
\hline $\begin{array}{l}\text { Observed/felt effects of climate variability } \\
\text { on upland farming }\end{array}$ & Weighted Mean & \multicolumn{1}{c}{ Interpretation } \\
\hline Poor soil & 2.11 & Sometimes experienced \\
Low yield & 2.11 & Sometimes experienced \\
Water scarcity & 2.12 & Sometimes experienced \\
Emergence of pests & 2.72 & Always experienced \\
Poor yield quality & 2.13 & Sometimes experienced \\
Scarcity of food & 2.63 & Always experienced \\
Depletion of natural resources & 2.06 & Sometimes experienced \\
\hline Legend: $0.50-1.50-$ never 1.51- 2.50- sometimes & $2.51-3.50-$ always &
\end{tabular}

\subsection{Traditional knowledge employed to adapt to climate variability}

Traditional knowledge employed to adapt to climate variability refers to the extent to which the Buhids had employed them to cope with the effects of climate variability. Extent of application of local knowledge was rated using 3-point scale: 3 (always), 2 (sometimes), and 1 (never). Table 3 presents the traditional knowledge employed by the Buhids to adapt to effects of climate variability on upland farming.

In terms of poor soil, the Buhids "always employed" the finding of a suitable area for cultivation (mean=2.64). This is especially in the case of swidden farming where fallowing is not observed. The soil becomes acidic when it is continuously cultivated. 
When the yield is no longer good, the Buhids find another area to cultivate. However, due to shrinking land area for cultivation and ballooning population, the farmers have no option but to continuously utilize the land for food production.

Table 3. Traditional knowledge employed to adapt to effects of climate variability on upland farming.

\begin{tabular}{|c|c|c|}
\hline $\begin{array}{l}\text { Traditional knowledge employed to adapt to effects } \\
\text { of climate variability on upland farming }\end{array}$ & $\begin{array}{l}\text { Weighted } \\
\text { Mean }\end{array}$ & Interpretation \\
\hline \multicolumn{3}{|l|}{ Poor soil } \\
\hline - $\quad$ Find suitable area for cultivation & 2.64 & Always employed \\
\hline \multicolumn{3}{|l|}{ Low yield } \\
\hline - $\quad$ Ritual (animal offering) & 1.09 & Sometimes employed \\
\hline - Change seeds & 2.61 & Always employed \\
\hline \multicolumn{3}{|l|}{ Water scarcity } \\
\hline - $\quad$ Ritual (daniw) & 1.83 & Sometimes employed \\
\hline - $\quad$ Plant drought resistant crops & 2.07 & Sometimes employed \\
\hline \multicolumn{3}{|l|}{ Emergence of pests } \\
\hline - Use of lapsik & 2.16 & Sometimes employed \\
\hline - Picking of tiyangaw (rice bugs) & 1.54 & Sometimes employed \\
\hline - Use of repellant (dead frog) & 1.76 & Sometimes employed \\
\hline - Burning of amuyong (Giniothalamus amuyon) & 2.53 & Always employed \\
\hline \multicolumn{3}{|l|}{ Poor yield quality } \\
\hline - Ritual & 1.85 & Sometimes employed \\
\hline - $\quad$ Change seeds & 2.60 & Always employed \\
\hline \multicolumn{3}{|l|}{ Lack of food } \\
\hline - $\quad$ Store rice in dungdong & 2.83 & Always employed \\
\hline - $\quad$ Eat rice substitutes (banana, root crops) & 2.67 & Always employed \\
\hline \multicolumn{3}{|l|}{ Depletion of natural resources } \\
\hline - $\quad$ Replant trees & 2.67 & Always employed \\
\hline Overall Mean & 2.05 & Sometimes employed \\
\hline
\end{tabular}

Legend: 0.50-1.50- never; 1.51- 2.50- sometimes; 2.51-3.50-always

It is worthy to note that the Buhids do not employ cosposting nor use animal manure to address poor soil. This is in accordance to their belief that nature restores itself. This understanding is common among the IPs. They rely on natural vegetation to regain the condition of the soil. The Buhids addressed low yield and poor yield quality through animal's blood offering ritual. The blood is spilled into the seeds before sowing. They belived doing this will improve crop yield. They also "always employed" changing of seeds by of availing improved ones from their comrades in the community.

Like the IP of Ghana, Africa [4], the Buhids cope with water shortages by planting drought-resistant plants. But the Buhids also "sometimes employed" ritual called daniw. Daniw is a god whom they prayed for help. It can be noticed that despite the Buhids' conversion to Christianity, they still observe their indigenous way of worhips. 
About $80 \%$ of the Buhids in the study areas are Catholics while the rest belong to other Christian denominations.

The problem on emergence of pests is addressed by the Buhids through the use of lapsik, picking tiyangaw (rice bugs), use of dead frog as repellant, and burning of amuyong (Giniothalamus amuyon). Lapsik is an improvised mouse trap. Tiyangaw are picked and threaded using coconut midribs and pierced in the middle of the farm to ward off other insects. Dead frog repellant is also done by posting the dead animal in the middle of the farm. Amuyong is a native tree with dark bark. The burned bark has a foul smell which is also used to drive insects off the farm.

Lack of food is always a problem of IPs being subsitence farmers. They store rice in dungdong, an elevated structure with one post wrapped in galvanized iron to prevent the rats from climbing and feeding on the grains. They also eat rice subtitutes especially wild yam (Dioscorea villosa), which is available year-round. Fresh wild yam is chopped and cleansed in free flowing water to remove poisonous substances. The chips are sun-dried and stocked for tigkiriwi (lean) months, which normally occur after planting and before harvesting seasons. The Buhids recognized depletion of natural resources as a consequence of their economic activities particularly swidden farming. The good thing about them is they do not engage in charcoal making that is rampant in other IP communities.

\subsection{Socio-economic characteristccs and traditional knowledge on farming to adapt climate variability}

Table 5 presents the association between the Buhid farmers' socio-economic characteristics and the traditional knowledge employed to adapt to effects of climate variability on upland farming. The results revealed a significant correlation of organizational affiliation $\left(\chi^{2}\right.$ comp. $=41.96 ; \chi^{2}$ crit $\left.=7.82\right)$, relevant trainings and seminars attended $\left(\chi^{2}\right.$ comp. $=49.51 ; \chi^{2}$ crit $\left.=7.82\right)$, and involvement to community activity $\left(\chi^{2}\right.$ comp.49.66; $\chi^{2}$ crit $\left.=7.82\right)$ with the traditional knowledge employed to adapt to effects of climate variability on upland farming. This suggests that the learning and experience gained by Buhids through non-formal training and involvement in community affairs have connection to how they respond to effects of climate variability on upland farming.

Table 5. Test of association between Buhid Mangyans' socio-economic characteristics and traditional knowledge employed to adapt to effects of climate variability on upland farming.

\begin{tabular}{lccc}
\hline \multicolumn{4}{c}{ Traditional Knowledge Employed on Upland Farming } \\
\cline { 2 - 4 } to Adapt to Effects of Climate Variability & \\
Socio-economic characteristics & Comp. $\chi^{\mathbf{2}}$ & Crit. $\boldsymbol{\chi 2}^{\mathbf{2}}$ & Interpretation \\
\hline Age & 2.09 & 5.99 & Not significant \\
$\begin{array}{l}\text { Household size } \\
\begin{array}{l}\text { Community organizations' } \\
\text { membership }\end{array}\end{array}$ & 1.26 & 5.99 & Not significant \\
$\begin{array}{l}\text { Trainings and seminars'relative to } \\
\text { limate variability adaptation }\end{array}$ & 41.96 & 7.82 & Significant \\
$\begin{array}{l}\text { attended } \\
\begin{array}{l}\text { Community involvement in climate } \\
\text { variability adaptation }\end{array}\end{array}$ & 49.51 & 7.82 & Significant \\
\hline
\end{tabular}




\section{Conclusion}

Based on the findings found in the study, the following conclusions are drawn: the Buhid farmers are either young and midddle-aged who had varying household sizes. Most are neither affiliated to community organizations nor had attended training and seminars related to climate variability adaptation and nor are involved in community adaptation activities. The Buhid farmers have experienced to some extent the effects of climate variability on several aspects of upland farming. A number of adaptation strategies are employed by Buhid farmers on swidden farming to cope with the felt experience relative to climate variability. Organizational affiliation, attendance to trainings and seminars related to climate variability, and involvement in community adaptation activities are associated to Buhids' traditional knowledge employed in adapting to effects of climate variability on upland farming. In the light of the findings, the following are recommended: The Buhid farmers' wide array of traditional knowledge on upland farming can be utilized in coming up with community-based adaptation strategies. The IPs intimate knowledge of the environment make them valuable actors in climate variability adaptation. Exhaustive study on this concern can be conducted particularly on other IKs possesed by the Buhids. Their being able to link the behavior of the animals with the conditions of the environment can serve as early warning systems. This will serve as important inputs in designing disaster risks and management programs.

\section{References}

[1] Ajani, E. N., Magbenka, R. N. \& Okeke, M. N. (2013, March 19). Use of Indigenous Knowledge as a Strategy for Climate Change Adaptation among Farmers in subSaharan Africa: Implications for Policy. Asian Journal of Agricultural Extension, Economics \& Sociology. 2(1):23-40, Article No. AJAEES. 2013:003. Retrieved November 19, 2015, from http:/ / africanclimate.net/sites/default/ files / Ajani_Use\% 20of\%20indigenous\%20 knowledge.pdf

[2] Claxton, M. (2010). Indigenous Knowledge and Sustainable development. Retrieved April 4, 2015, from https//sta.uwiedu/.../Sept 1_Indigenous $\% 20$ Culture $\% 20$ and $\%$ sus

[3] Focus on the Global South-Philippines. (23 February 2015). Right to Food and Food Security in the Philippines: What the Numbers Say. Retrieved May 30, 2015, from http:/ / focusweb.org/ content/right-food-and-food-security-philippines-whatnumbers-say

[4] Gyampoh, B. A., Amisah, S., Idinoba, M. and Nkem, J. (u.d.). Using traditional knowledge to cope with climate change in rural Ghana. Retrieved April 4, 2015, from http://www.fao.org/docrep/011/i0670e/i0670e14.htm

[5] International Fund for Agricultural Development (IFAD). (2000). Rural Poverty in the Philippines. Retrieved April 2, 2015, from www.ruralpovertyportal.org

[6] International Fund for Agricultural Development (IFAD). (November 2012). Country Technical Notes on Indigenous Peoples' Issues. Republic of the Philippines. Retrieved April 5, 2015, from ifad.org./english/indigenous/pub/documents/notes/philippines.pdf

[7] Lopez, V. B. (u.d.). From "Tribes" to Peasants and Entrepreneurs: A Study of the Buhid Differential Responses to Change. Retrieved April 4, 2015, from asj.upd.edu.ph/...ASJ15.../lopez-tribes-peasants-entrepreneurs-buhid.pdf 
[8] NewCAPP. (2014). The ties that bind: The Buhid Mangyan People of Mindoro, their Sacred Lands and Medicine Mountain. Retrieved November 18, 2015, from newcapp.files.wordpress.com/2014/02/buhidmangyan1.pdf

[9] Raygorodetsky, G. (2011, December 13). Why Traditional Knowledge Holds the Key to Climate Change. United Nations University. Shibuya-ku, Tokyo, Japan. Retrieved November 21, 2015, from http://unu.edu/publications/articles/whytraditional-knowledge-holds-the-key-to-climate-change.html

[10] Zamora, O. B., De Guzman, L. E. P., Nelson, G. L. M., Tatlonghari, R. V., Espaldon, M. V. O., Talubo, J. P. P., \& Inzon, M. R. B. Q. (u.d.). Documenting and Promoting Indigenous Agricultural Knowledge and Climate Change Adaptation in Selected Areas in the Philippines Toward Enhancing Community-Level Food Security. Retrieved April 5, 2015, from http://ovcre.uplb.edu.ph/index.php?option=com_k2Eview=itemEid=270:documentingand-promoting-indigenous-agricultural-knowledge-and-climate-change-adaptation-inselected-areas-in-the-philippines-toward-enhancing-community-level-foodsecurityEitemid $=229$ 